\title{
ANALISA TEGANGAN SCREW CONVEYOR PADA MESIN PENCAMPUR GARAM DAN IODIUM SESUAI SNI 3556 DENGAN METODE ELEMEN HINGGA
}

\author{
Aenor Rofeg \\ Program Studi Teknik Mesin, Fakultas Teknik \\ Universitas Muria Kudus \\ Email: Aenor_rofeg@yahoo.com \\ Masruki Kabib \\ Program Studi Teknik Mesin. Fakultas Teknik \\ Universitas Muria Kudus \\ Email: masruki.kabib@umk.ac.id
}

\begin{abstract}
ABSTRAK
Mesin pencampur garam dan iodium adalah suatu alat yang digunakan untuk pencampuran garam dan iodium dengan menggunakan screw conveyor dengan aliran $\mathrm{KIO}_{3}$, disyaratkan sistem pencampurannya secara kontinyu agar pencampuran garam dan iodium dapat homogen untuk memenuhi standar SNI 3556. Kekuatan screw conveyor menjadi faktor pertimbangan perlunya pengkajian lanjut tentang sebab kegagalannya, akibat faktor internal atau faktor eksternal, seperti pengaruh bahan material, pengoperasia, lingkungan atau pembebanan serta mengetahui seberapa besar nilai pembebanan dan kerusakannya. Tujuan penelitian ini adalah menganalisa tegangan screw conveyor dengan metode elemen hingga. Metode yang di gunakan adalah melakukan analisa tegangan, displacement dan safety factor dengan beban statis pada screw conveyor menggunakan metode lemen hingga. Salah satu hal utama mekanika bahan adalah menyelidiki tahanan dalam berupa reaksi atau gaya-gaya dalam dan deformasi. Hasil penelitian adalah tegangan maksimun von misses $8.16969 \mathrm{MPa}$, displacement yang terjadi pada screw conveyor mesin pencampuran garam dan iodium adalah sebesar $0,0792 \mathrm{~mm}$ dan safety factor $15 \mathrm{ul}$. Tegangan dan displacement masih sangat aman dari batas kritis dan mesin dapat beroperasi dengan baik.
\end{abstract}

Kata kunci: beban statis; garam dan iodium; tegangan; screw conveyor; software inventor.

\begin{abstract}
ABSTRAK
The salt and iodine mixing machine is a device used for mixing salt and iodine by using a screw conveyor with a KIO3 stream, it is required that the mixing system be continuous so that the mixing of salt and iodine can be homogeneous to relevan with 3556 SNI standar. The strenght of screw conveyor is used this consideration factor, it is necessary to have further assessment about the cause of the failure, whether due to internal factors or external factors, such as the effect of materials, operation, environment or loading and know how much the value of loading and damage. This purposeof study is to analyze the screw conveyors stress with Finite elemen Method. The research method was used Stress analysis with the static load on the screw conveyors use Finite element method. One of the major mechanics of materials is to investigate the resistance in the form of reactions or inner forces and deformation. The result of research was maximun von mises stress $8.16969 \mathrm{MPa}$, displacement occurring on the screw conveyors of the salt and iodine mixing machine is $0.0792 \mathrm{~mm}$ and safety factor $15 \mathrm{ul}$. The stress and displacement was still very safe from a critical limit and the machine can operate with either.
\end{abstract}

Keywords: static load; salt and iodine; stress; screw conveyor; inventor software.

\section{PENDAHULUAN}

Kebutuhan garam krosok nasional semakin meningkat seiring dengan pertambahan penduduk dan perkembangan industri di Indonesia. Untuk mencukupi kebutuhan ini perlu peniingkatkan produksi garam krosok dan kualitasnya. Alat pencampur dan pengangkut garam dalam industri sangat bermacam-macam, tergantung dari garam yang akan dicampur dan dipindahkan, serta lokasi pemindahan bahan tersebut. Pencampuran garam dan iodium harus memenuhi standar SNI 3556 [1]. Proses pencampuraan garam dan iodium yang homogen dapat menggunakan sistem injeksi. Pada sistem injeksi iodium dilarutkan dalam cairan kemudian di injeksikan pada garam [2]. Untuk memenuhi standar SNI diperlukan juga proses pencucian dan pengayakan garam terlebih dahulu [3]. Kadar iodium yang homogen sangat penting sekali, 
untuk mencegah pengurangan iodium saat di masak [4]. Metode pencampuran garam dan iodium yang baik adalah dry mixing [5]. Setiap alat pencampur dan pengangkut garam dan iodium memiliki spesifikasi tertentu.

Proses pencampuran dan pengangkutan garam dapat menggunakan berbagai jenis konveyor, yang banyak digunakan di industry adalah 1). Screw conveyor yaitu merupakan suatu alat untuk mengangkut material berbentuk bubur dan butiran halus dengan memutar sudu berbentuk screw. 2). Belt conveyor yaitu terdiri dari sabuk yang berbentuk rata dan di hubungkan 2 buah rol yang memindahkan material secara mendatar. 3).Vibrating conveyor merupakan suatu alat yang mengangkut material dengan cara getaran, sehingga butiran bahan akan berpindah dan bercampur. 4). Bucket elevator adalah suatu alat pemindah bahan dari posisi rendah ke ketinggian tertentu conveyor. Salah satu tipe conveyor yang sering digunakan dalam industry untuk pencampuran garam dan pengangkutan adalah screw conveyor

Bahan garam krosok yang digunakan di indutri merupakan bahan yang berat, berupa butiran dan bersifat korosif, Untuk memindahkan dan pencampiran garam krosok diperlukan alat transportasi yang sesuai. Alat pengangkut dan pencampur garam secarfa manual, kurang efektif, karena tenaga manusia sangat terbatas. Srew conveyor digunakan untuk mencampur dan mengangkut bahan garam krosok industri yang berbentuk padat. Screw conveyor mampu melakukan pencampuran garam dan iodium secara homogeny dengan mekanisme screw injeksi [6]. Screw conveyor yang memiliki sistem kerja utama ada sudu berbentuk helik yang menyatu pada poros dan diputar menggunakan motor penggerak dengan menggunakan sistem trransmisi.

Kekuatan sudu screw dalam menerima gaya dorong yang disebabkan material dan putaran mesin yang sangat penting dalam memindahkan garam krosok. Kelendutan yang terjadi dapat menyebabkan getaran pada mesin. Lendutan pada poros yang terlalu besar berakibat gesekan antara chasing dan flighting sehingga logam hasil gesekan mengkontaminasi material angkut..Untuk menunjang kinerja mesin screw konveyor pemilihan bantalan sangat mendukung sekali sehingga memperoleh umur mesin yang lebih panjang.

Gaya dorong yang di hasilkan oleh putaran sudu screw dapat menggerakkan dan memindahkan garam krosok. Besarnya gaya dorong dipengaruhi torsi dan kecepatan putar dari motor penggerak. Gaya dorong pada garam krosok berpengaruh pada sudu screw yaitu dapat menimbulkan deformasi pada sudu screw. Deformasi ini akibat tegangan yang melebihi ultimate tensile strenght pada sudu screw . Tegangan ini dapat menyebabkan terjadinya deformasi plastis yang juga berdampak terhadap fungsi dan kinerja dari screw konveyor. Pemilihan bahan sudu screw harus tepat sehingga dapat menahan gaya dorong yang dihasilkan oleh material dan kecepatan putar mesin, serta tahan terhadap korosi.

Kemampuan screw conveyor dalam memindahkan garam krosok juga dipengaruhi adanya lendutan yang terjadi pada poros screw dan chasing. Antara daun screw dan chasing screw conveyor perlu di berikan jarak tertentu agar tidak terjadi gesekan.Jaraak yang terlalu longgar dapat mengakibatkan garam krosok yang tertinggal di chasing. Material garam krosok yang tertinggal di dalam chasing dapat emngganggun kinerja screw konveyor. Analisa kelendutan (displacement) dilakukan untuk mengetahui apakah terjadi gesekan antara daun screw dan chasing. Gesekan antara keduanya juga dapat terkontaminasi garam krosok yang diangkut yaitu meningkatkan kandungan zat besinya.Jika material angkutnya berupa Garam, hal ini sangat berbahaya untuk kesehatan manusia.

Tujuan penelitian ini adalah untuk menganalisa tegangan von mises, displacement dan safety sactor pada screw conveyor dengan metode elemen hingga. Analisa tersebut dilakukan dengan metode elemen hingga menggunakan software autodesk inventor professional 2015. Software ini dapat digunakan membuat pemodelan mesin yang kemudian dilakukan analisis tegangan sudu screw akibat gaya yang dihasilkan dan juga mampu menganalisis besarnya kelendutan yang terjadi pada poros pipa dan chasing [7]. Analisa beban dinamis pada screw konveyor dapat mengetahui variasi pembebanan yang terjadi pada screw konveyor serta besarnya beban yang ditopang oleh bearing [8]. Dengan analisa ini dapat diketahui apakah kondisi yang terjadi pada screw konveyor masih dalam kondisi aman dan mesin dapat bekerja dengan maksimal.

\section{METODOLOGI PENELITIAN}

\subsection{Jenis Material}

Material yang dipergunakan pada penelitian ini adalah Stainless Steel 304 dengan poros screw berdiameter 25,4 $\mathrm{mm}$ dan tebal daun Screw $2 \mathrm{~mm}$. 


\subsection{Spesifikasi Stainless Steel 304}

Dimensi screw conveyor sebagaimana ditunjukkan pada gambar 1, dengan spesifikasi material Stainlees Steel 304 l sebagaimana ditunjukkan tabel 1, 2 dan 3.

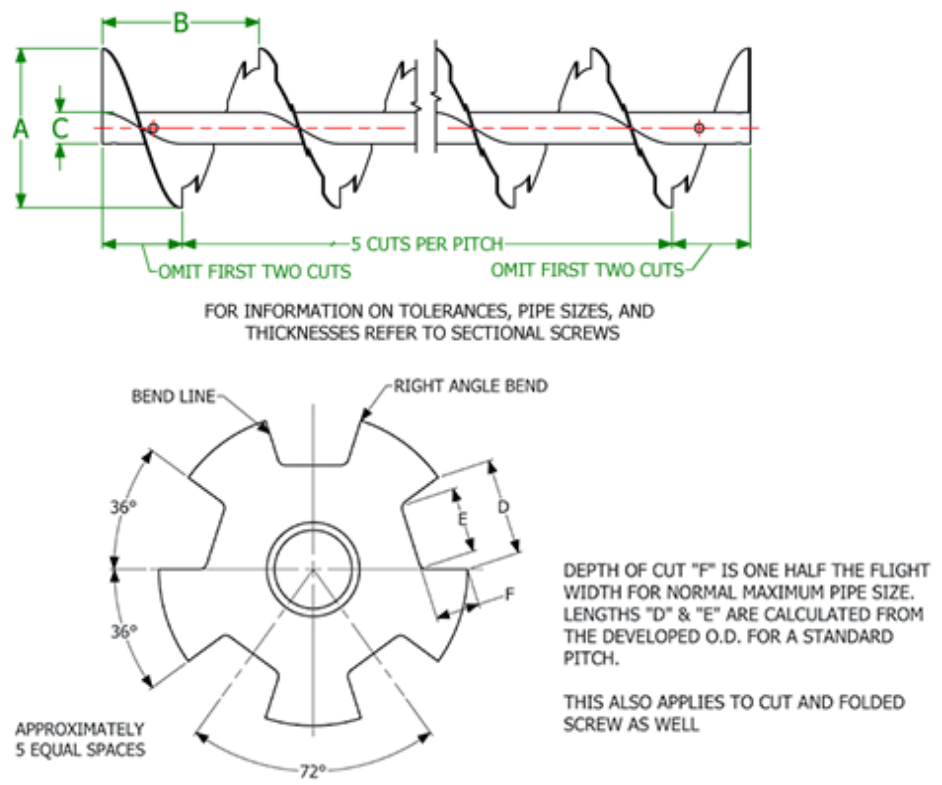

Gambar 1. Dimensi Screw Conveyor

Tabel 1. Komposisi spesifkasi tipe SS304, berdasarkan ASTM A240[9]

\begin{tabular}{llllllllll}
\hline Grade 304 & $\boldsymbol{C}$ & $\boldsymbol{M n}$ & $\boldsymbol{S i}$ & $\boldsymbol{P}$ & $\boldsymbol{S}$ & $\boldsymbol{C r}$ & $\boldsymbol{M o}$ & $\boldsymbol{N i}$ & $\boldsymbol{N}$ \\
\hline $\operatorname{Min}(\%)$ & - & - & - & - & - & 17.5 & - & 8.0 & - \\
\hline $\operatorname{Max}(\%)$ & 0.07 & 2.0 & 0.75 & 0.045 & 0.030 & 19.5 & - & 10.5 & 0.10 \\
\hline
\end{tabular}

Tabel 2. Spesifikasi material property tipe SS304, berdasarkan ASTM A240

\begin{tabular}{lllllll}
\hline Grade & $\begin{array}{l}\text { Tensile } \\
\left(\mathbf{N} / \mathbf{m m}^{2}\right)\end{array}$ & Strenght & $\begin{array}{l}\text { Yield strenght } \\
\left(\mathbf{N} / \mathbf{m m}^{2}\right)\end{array}$ & $\begin{array}{l}\text { Elongation (\% } \\
\text { In 50mm })\end{array}$ & $\begin{array}{l}\text { Rockwell } \\
\text { B (HRB) }\end{array}$ & $\begin{array}{l}\text { Brinell } \\
(\text { HB })\end{array}$ \\
\hline SS304 & 515 & 205 & 40 & 92 & 201 \\
\hline
\end{tabular}

Tabel 3. Physical properties tipe SS304, berdasarkan ASTM A240

\begin{tabular}{lllllll}
\hline Grade & $\begin{array}{l}\text { Massa } \\
\text { jenis } \\
\left(\mathbf{K g} / \mathbf{m}^{2}\right)\end{array}$ & $\begin{array}{l}\text { Modulus } \\
\text { Elastisitas } \\
(\mathbf{G p a})\end{array}$ & $\begin{array}{l}\text { Konduktivitas } \\
\text { termal } \\
(\mathbf{W} / \mathbf{m}-\boldsymbol{k})\end{array}$ & $\begin{array}{l}\text { Specific } \\
\text { Heat } \\
(\mathbf{J} / \mathbf{K g} . \mathbf{K})\end{array}$ & $\begin{array}{l}\text { Melting } \\
\text { Range } \\
\left({ }^{\boldsymbol{}} \boldsymbol{F}\right)\end{array}$ & $\begin{array}{l}\text { Resivits } \\
\text { listrik } \\
(\boldsymbol{n} \boldsymbol{\Omega} \mathbf{m})\end{array}$ \\
\hline SS304 & 7900 & 193 & 16.3 & 500 & 2500 & 720 \\
& & & & & & \\
\hline
\end{tabular}

\subsection{Desain Screw Mesin Pencampur Garam dan Iodium}

Bentuk screw dari mesin screw conveyor adalah Flight Cut screw. Gambar desain dari bentuk screw ini sebagaimana ditunjukkan pada gambar 2. 


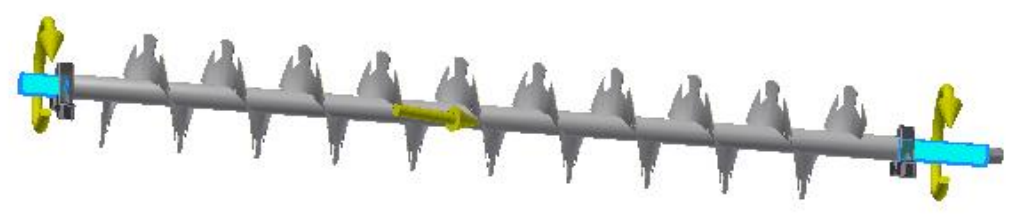

Gambar 2. Desain Flight Cut Screw

\section{HASIL DAN PEMBAHASAN}

Hasil analisa statik menggunakan metode elemen hingga dengan software Inventor dapat diketahui tegangan maksimal dan minimal yang terjadi pada screw conveyor yang dianalisa. Dari hasil simulasi juga di dapatkan nilai stress, displacement dan safety factor. Pada proses pemodelan dan simulasi, screw conveyor mendorong garam mendapatkan gaya dari pembebanan sebesar $200 \mathrm{~N}$ pada screw dan $100 \mathrm{~N}$ pada bearing.

\subsection{Displacement}

Besarnya displacement screw pada proses pencampuran garam dan iodium dapat di tunjukkan pada gambar 3.

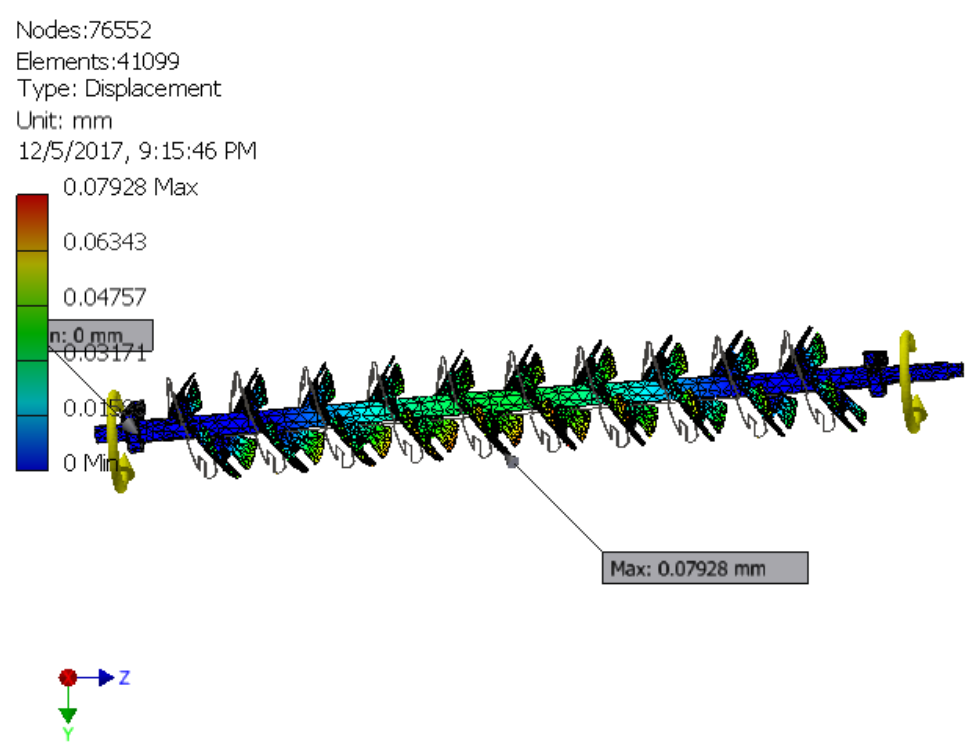

Gambar 3. Tampilan Displacement

Dari hasil analisa simulasi pada gambar 3 menunjukkan bahwa distribusi pembeban keseluruh bagian screw. Hasil Analisis simulasi menunjukkan total deformasi terbesar ada pada screw conveyor dengan gaya dorong maxsimum adalah 0,079283 mm. Dan total deformasi terkecil ada pada bagian fix contrain / daerah tumpuan bearing yaitu sebesar $0 \mathrm{~mm}$.

\subsection{Von Misses Stress}

Analisa tegangang von misses pada screw conveyor untuk proses pencampuran garam dan iodium ditunjukkan pada gambar 4. 

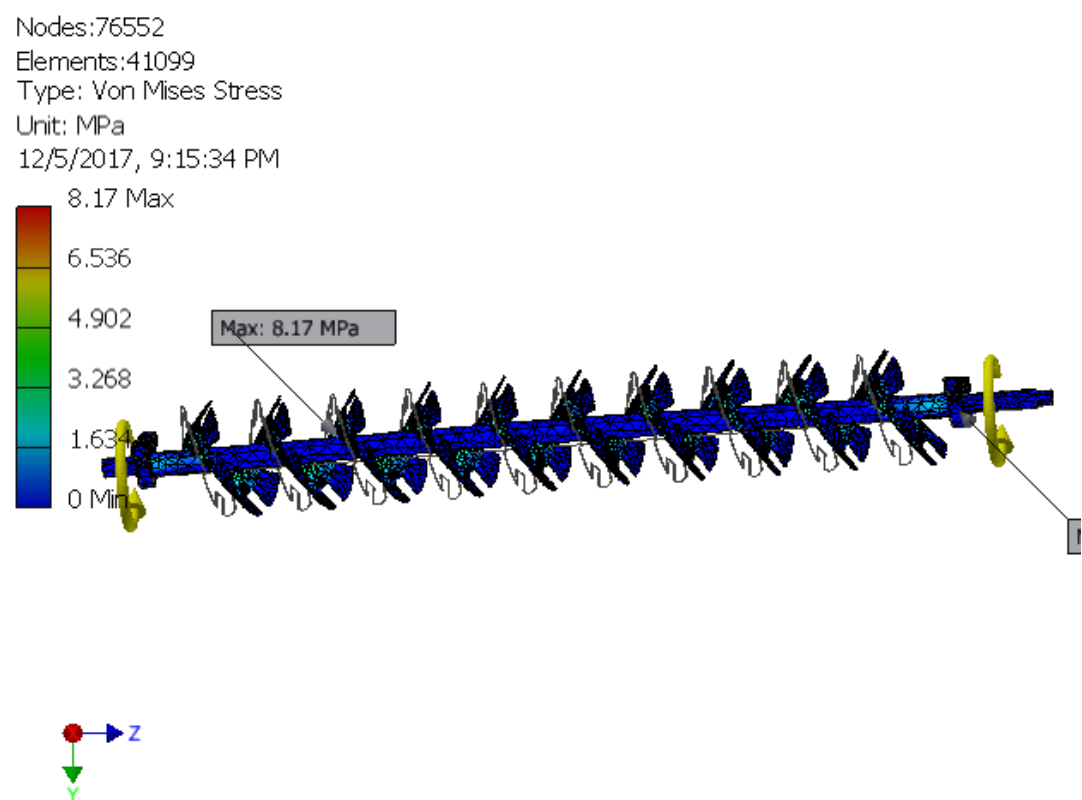

Gambar 4. Analisa Tegangan Von Misses

Pada gambar 4 menunjukkan distribusi tegangan keseluruh bagian screw. Hasil simulasi menunjukkan bahwa Von Misses Stress maxsimum terjadi pada pada tumpuan poros screw conveyor yaitu sebesar 8,16969 MPa. Pada hasil dari Von Misses Stress minimum terjadi pada sebagian besar bearing tersebut yaitu sebesar 0 Mpa.

\subsection{Safety Factor}

Hasil analisa safety factor pada screw conveyor untuk proses pencamopuran garam dan iodium sebagaimana ditunjukkan pada gambar 5 .

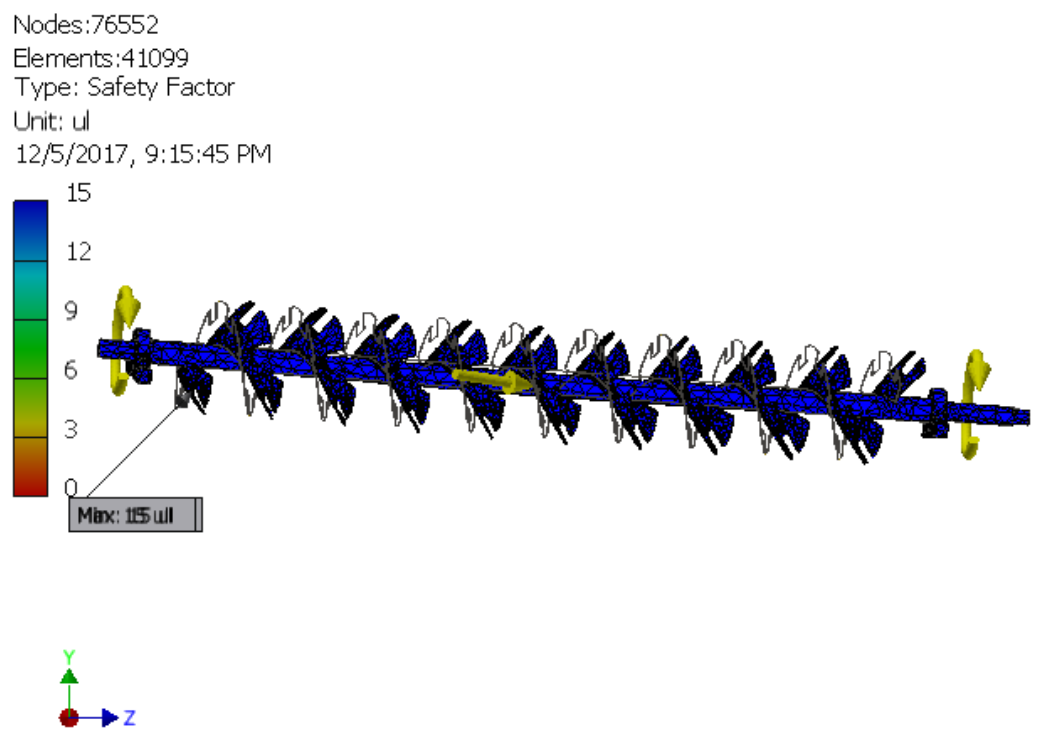

Gambar 5. Analisa Safety Factor

Dari data diatas menunjukan bahwa safety factor minimal 15 ul dan maksimal berada pada nilai 15 ul. Secara keseluruhan hasil analisa simulasi dengan metode elemen hingga ditunjukkan pada tabel 4. 
Tabel 4. Hasil analisa simulasi

\begin{tabular}{lll}
\hline Name & Minimum & Maximum \\
\hline Displacement & $0.000 \mathrm{~mm}$ & $0.079283 \mathrm{~mm}$ \\
Von mises stress & $0 \mathrm{MPa}$ & $8.16969 \mathrm{MPa}$ \\
Safety Factor & $15 \mathrm{ul}$ & $15 \mathrm{ul}$ \\
\hline
\end{tabular}

Dari tabel 4 terlihat bahwa displacement pada pembebanan maxsimum yaitu saat tengangan gaya dorong screw conveyor adalah $0.079283 \mathrm{~mm}$, sedangkan angka terendah yaitu $0.000 \mathrm{Mpa}$. Nilai displacement ini tergolong kecil sehingga tidak berpengaruh pada proses pencampuran garam dan iodium, dan aman terhadap screw pada saat beroperasi.

Pada analisa tegangan Von misses, tegangan maxsimum terjadi pada tumpuan poros screw conveyor sebesar 8,16969 MPa, Von mises stress minimum terjadi pada tumpuan bearing poros screw conveyor sebesar $0 \mathrm{MPa}$. Hasil ini menunjukkan bahwa poros mampu menahan beban dari ketiga sumbu pembebanan $\mathrm{x}, \mathrm{y}$ dan $\mathrm{z}$.

Pada analisa Safety Factor maxsimum angka terbesar terjadi pada poros screw conveyor yaitu sebesar 15 ul, sedangkan Safety Factor minimum angka terbesar poros bearing screw conveyor yaitu sebesar 15 ul. Hal ini menujukkan bahwa pada pembebanan proses pencampuran garam dan iodium material dan dimensi yang digunakan dinyatakan aman.

\section{KESIMPULAN}

Berdasarkan hasil dari simulasi analisa tegangan screw conveyor dengan metode elemen hingga untuk pencampur garam dan iodium yang menggunakan jenis material stainless steel 304, menghasilkan distribusi tegangan keseluruh screw conveyor. Hasil analisis di dapatkan nilai displacement maksimal sebesar 0,0792 mm. Tegangan Von misses maksimum 8,16969 MPa dan safety factor 15 ul. Sehingga dapat dinyatakan screw conveyor memenuhi syarat dan aman untuk proses pencampuran garam dan iodium.

\section{DAFTAR PUSTAKA}

[1] M. Akhiruddin, "nalisis Kadar Kalium Iodat (KIO3) dalam Garam Dapur dengan Menggunakan Metode Iodometri yang Beredar di Pasar Ujung Batu Kabupaten Rokan Hulu," Universitas Islam Negeri Sultan Syarif Kasim Riau, 2011.

[2] W. Broto and H. Kusumayanti, "Perbaikan Proses Iodisasi Garam Dengan Sistem Injeksi," Gema Teknol., pp. 78-81, 2007.

[3] M. Nur, I. Marhaendrajaya, Sugito, T. Windarti, Arnelli, and R. Hastuti, "Pengayaan Yodium dan Kadar NaCl pada Garam Krosok Enrichment of Iodium and Sodium Cloride in the Traditional Salt become," J. Sains dan Mat., vol. 21, no. 1, pp. 1-6, 2013.

[4] C. Wisnu, "Determination of iodine species content in iodized salt and foodstuff during cooking," Int. Food Res. J., vol. 15, no. 3, pp. 325-330, 2008.

[5] S. Ranganathan, S. Sundaresan, I. Raghavendra, and S. Kalyani, "Dry mixing technique for the large scale production of iodine fortified salt in India," Asia Pacific Journal of Clinical Nutrition, vol. 6, no. 2. pp. 92-94, 1997.

[6] Hartati et al, "Yodisasi garam rakyat dengan sistem screw injection," Gema Teknol., vol. 17, no. 4, pp. 160$163,2014$.

[7] A. R. Basyir, "Perancangan Unit Transfer (Secrew Cobveyor) Pada Mesin Pengisi Polibag Untuk Meningkatkan Efektifitas kinerja Di Bidang Pembibitan,” J. Citra Widya Edukasi, vol. IX, no. 2, pp. 60-67, 2017.

[8] Sabardiyanto and N. Iskandar, "Analisis Mekanik Screw Conveyor Tubula Berdiameter 200 mm,” Tek. Mesin, vol. 4, no. 2, pp. 178-186, 2016.

[9] American Society for Testing and Materials, "ASTM A240: Standard Specification for Chromium and Chromium-Nickel Stainless Steel Plate, Sheet , and Strip for Pressure Vessels and for General Applications," ASTM Int., vol. I, p. 12, 2004. 